\title{
Association between Posttraumatic Stress Disorder and Preflood Behavioral Characteristics among Children Aged 7-15 Years in Hunan, China
}

\author{
Minning Peng ${ }^{a, b}$ Aizhong Liu ${ }^{a}$ Jia Zhou ${ }^{a}$ Shiwu Wen ${ }^{a, c}$ Shuoqi Li ${ }^{a}$ \\ Tubao Yang ${ }^{a}$ Xingli Li ${ }^{a}$ Xin Huang ${ }^{a}$ Benjamin Abuaku ${ }^{a}$ Hongzhuan Tan $^{a}$ \\ ${ }^{a}$ Department of Epidemiology and Biostatistics, School of Public Health, Central South University, \\ and ${ }^{b}$ Central South University Press, Changsha, China; ${ }^{c}$ Departments of Obstetrics and Gynecology, \\ University of Ottawa Faculty of Medicine, Ottawa, Ont., Canada
}

\section{Key Words}

Flood · Posttraumatic stress disorder • Behavioral characteristics

\begin{abstract}
Objective: To explore the relationship between posttraumatic stress disorder (PTSD) and preflood behavioral characteristics among children aged 7-15 years in Hunan, China. Subjects and Methods: In 2000, a retrospective study was carried out among children who had been exposed to the 1998 floods in Hunan. A multistage sampling method was used to select subjects from the flood-affected areas. A structured questionnaire administered to the children selected was used to diagnose PTSD based on the DSM-IV criteria. A parent questionnaire was used to measure preflood behavioral characteristics related to health, behavioral, and habit problems. The association between PTSD and preflood behavioral characteristics was assessed using $\chi^{2}$-tests and multivariate logistic regression. Results: $A$ total of 7,038 children from 13,450 households, aged 7-15 years, were investigated. The overall prevalence of PTSD was $2.05 \%$. Generally, the PTSD-positive rate increased with increasing scores for behavioral characteristics. Conclusion: Preflood behavioral characteristics are an important factor influenc-
\end{abstract}

ing the prevalence of PTSD among children exposed to floods. It is therefore necessary to give special attention to children with behavioral problems in order to reduce the psychological impact of floods.

Copyright $\odot 2011$ S. Karger AG, Basel

\section{Introduction}

Flooding is a common phenomenon and yet unrecognized as one of the severest forms of natural disasters, accounting for up to one half of all natural disasters in the world [1]. In China, floods occur frequently. A severe flood that struck China's Hunan province in 1998 lasted 45 days, left hundreds of thousands of residents homeless, and damaged many infrastructural and agricultural projects. Floods thus can lead to direct property and other economic losses, psychological injuries, physical injuries, and death. A common disorder among disaster victims, posttraumatic stress disorder (PTSD), is a severe and complex disorder precipitated by exposure to psychologically distressing events [2]. It is characterized by persistent intrusive memories about the traumatic event, persistent avoidance of stimuli associated with the trauma, and persistent symptoms of increased arousal [3]. For

\section{KARGER \\ Fax +4161306 1234 \\ E-Mail karger@karger.ch}

www.karger.com
(C) 2011 S. Karger AG, Basel

1011-7571/11/0204-0336\$38.00/0

Accessible online at:

www.karger.com/mpp
Dr. Hongzhuan Tan

Department of Epidemiology and Biostatistics

School of Public Health, Central South University

Changsha 410078 (China)

Tel. +86 7318885 8435, E-Mail tanhz99@qq.com 
decades the study of PTSD has focused mainly on traffic accidents, violent crimes, terrorist attacks, hurricanes, earthquakes, hijackings, rapes, and warfare with negligible focus on floods [4-7].

Although behavioral characteristics have been considered to be an important factor influencing an individual's reactions to stress and also having effect on PTSD, the majority of flood-related studies have assessed the impact of floods based mainly on property loss, mortality, and morbidity $[8,9]$. None of the few PTSD studies among flood victims has examined the relationship between PTSD and behavioral characteristics in children $[10,11]$. We therefore investigated preflood behavioral characteristics and their influence on PTSD among 7- to 15-year-old children exposed to the 1998 floods in $\mathrm{Hu}$ nan, China.

\section{Subjects and Methods}

\section{Study Population and Sampling}

Victims directly exposed to the 1998 summer floods in $\mathrm{Hu}-$ nan, China formed the target population. The study area covered the catchment area of Dongting Lake, located south of the middle reaches of the Yangzi River in southern China, a flood-prone area. The catchment area of Dongting Lake consists of 31 counties covering an area of $31,000 \mathrm{~km}^{2}$ with an estimated human population of 11.3 million. The study also covered 7 counties in western $\mathrm{Hu}$ nan province exposed to flash floods during the same year. The climatic conditions in the two study areas are subtropical in nature with an annual rainfall of 1,250-1,780 $\mathrm{mm}$ and an annual temperature of $15-18^{\circ} \mathrm{C}$. Residents of the two areas are mainly farmers with a low level of education.

A multistage sampling method was used to select study subjects. In the first stage of sampling, 7 of the 31 counties that suffered soaking and collapsed embankments (Yueyang, Lingxiang, Huarong, Qianlianghu, Ziyang, Anxiang, Datonghu) together with 1 of the 7 counties that experienced flash flooding (Longshan) were selected. In the second stage of sampling, $50 \%$ of towns from each of the 8 selected counties were randomly selected. In the third stage of sampling, $50 \%$ of villages from the selected towns were randomly selected. Finally, $50 \%$ of households from the selected villages were randomly selected. A total of 13,450 households were randomly selected for the study. All 7- to 15-year-old children in the selected households were included in our study. A total of 8 counties, 40 towns, 310 villages, 13,450 households, and 7,860 individuals aged $7-15$ years were selected for this study. Of the 7,860 selected study subjects, 7,038 (89.54\%) were interviewed. Of this group 3,730 (53.00\%) were males; 3,257 (46.28\%) were from soaked flood areas; 2,621 (37.24\%) were from collapsed flood areas, and 1,129 (16.04\%) were from flash flood areas.

Flooding was classified into three types: soaked flood, collapsed embankment, and flash flood, and these categories were divided into three groups in order of severity: mild (affected area $<50 \%$ of total village area), intermediate (affected area $50-75 \%$ of total village area), and severe (affected area $>75 \%$ of total village area).

\section{Survey Methods}

The survey was conducted between in January and May 2000. Trained investigators who worked at the local centers for disease control and prevention and who had a bachelor's degree or higher carried out face-to-face interviews using a structured questionnaire to obtain demographic data and ascertain PTSD. Investigators received on-site supervision from psychologists. A parent's questionnaire, which has been used in Chinese populations and proven to have good validity and reliability, was used to measure children's behavioral characteristics [12]. The project was approved by the ethics committee of Central South University.

The diagnosis of PTSD was made according to the fourth edition of the Diagnostic and Statistical Manual of Mental Disorders (DSM-IV) [3], which included 17 symptoms scored as $0=$ none, 1 = slight, 2 = moderate, $3=$ severe, and $4=$ extreme. Subjects with scores $\geq 2$ were defined as positive for a specific symptom. The 17 symptoms of PTSD were further divided into three groups, representing three diagnostic criteria, B, C, and D. Criterion B symptoms represented the reexperiencing cluster, namely: intrusive recollections (B1); repeated nightmares about floods (B2); acting as if the flood was occurring (B3); feeling worse when reminded of the flood (B4); reactivity to flood reminders (B5). Subjects were defined as B-positive if they had one or more symptoms in the B group. Criterion $\mathrm{C}$ symptoms represented the avoidance cluster, which included: efforts to avoid thoughts or feelings associated with the flood (C1); efforts to avoid activities that arouse recollections of the flood (C2); amnesia in regard to the flood (C3); diminished interest (C4); detachment or estrangement (C5); restricted range of affect (C6); sense of foreshortened future (C7). Subjects were defined as C-positive, if they had three or more symptoms in the $\mathrm{C}$ group. Criterion $\mathrm{D}$ symptoms represented the hyperarousal cluster, namely: difficulty falling or staying asleep (D1); irritability or anger (D2); difficulty concentrating (D3); hypervigilance (D4); exaggerated startle response (D5). Subjects were defined as D-positive if they had two or more symptoms in the D group. There were also criteria A and $\mathrm{E}$ for the diagnosis of PTSD. Criterion A represented exposure to a trauma outside the range of usual experience, and criterion E represented a disturbance lasting more than 1 month. Subjects were diagnosed to have PTSD, if criteria A, B, C, D, and E symptoms were all positive. We assessed all symptoms, including the time and duration of occurrence. The questionnaire used for PTSD had been tested in Chinese populations, and proven valid and reproducible [13]. It is worth mentioning that the selected children in our study completed questions on their PTSD themselves.

Behavioral characteristics of the selected children were assessed using a parent questionnaire [14] consisting of three parts: questions regarding health, behavior, and habit. Questions relating to health included 'headache', 'stomachache or vomiting', 'bronchial asthma or asthmatic attack', 'bed-wetting or pantwetting', 'defecating in bed or into pants', 'losing one's temper', 'refusing to attend school or weeping when going to school', and 'truancy'. Questions relating to behavior included 'difficulty in sitting quietly for a long time', 'hyperactivity, confusion or restlessness', 'often destroys personal or other people's things', 'often fights or quarrels with other children', 'other children don't like him', 'often worried', 'usually stays alone', 'sudden irritability or loss of temper', 'often in pain, unhappy or grieved', 'tics of face or limbs', 'often sucks thumb/finger', 'often bites fingernails', 'often difficult to supervise', 'lacks ideas', 'afraid of new things/environment', 'neurotic', 'lies often', and 'bullies other children'. Ques- 
tions relating to habit included 'stuttering', 'dysphasia', 'stealing', 'abnormal food intake', and 'dyscoimesis'. Each item was graded as follows: 0 = none, 1 = slight, 2 = severe or occurs frequently. The total score of all items was used as a measure of the behavior status of the subject, and the score for each category was the cumulative score for the corresponding items. Scores for the three behavioral characteristics were as follows: health questions $0-16$, behavioral questions $0-36$, and habit questions $0-10$. The overall/total scores ranged between 0 and 62 .

All interviewers participated in a 2-day training program that focused on the questionnaires. A working manual was provided to ensure that all interviewers had the same understanding of the questionnaire. The completed questionnaires were checked by the coordinator of the study. If a questionnaire was found to be incomplete or inconsistent, the interview was repeated for the same subject to reduce missing data as far as possible and improve the response rate.

\section{Statistical Analysis}

The characteristics of the study areas and study populations were first described. Then $\chi^{2}$-tests were used to compare rates of PTSD by gender, age-group, flood type and severity. The three parts of the parent questionnaire (health questions, behavioral questions, and habit questions) were categorized as 0 (score: 0 ), 1 (score: 1), 2 (score: 2 ), and 3 (score: $\geq 3$ ). Cumulative scores for all three parts were categorized as 0 (score: 0 ), 1 (score: 1-2), 2 (score: $3-5$ ), and 3 (score: $\geq 6$ ). The association between PTSD and behavioral characteristics was further analyzed using $\chi^{2}$-tests and multivariate logistic regression. The dependent variable was PTSD while the potential confounding variables considered in the regression analysis were age, sex (1: male; 2 : female), flood type (1: soaked flood; 2 : collapsed embankment; 3: flash flood, with soaked flood as the reference), flood degree (1: mild, 2: moderate; 3: severe), 'surrounded by the water and waited for rescue' (0: no; 1 : yes), 'saw somebody drowned by the flood' (0: no; 1 : yes), 'family members scattered by the flood' (0: no; 1 : yes), 'reopening of school delayed or changed school because of the disaster' (0: no; 1: yes). Categorical covariates were 'health questions score', 'behavioral questions score', 'habit questions score', and 'total score'. The adjusted odds ratio (OR) originating from the multivariate logistic regression was transformed into adjusted $\mathrm{RR}$ using the formula: $\mathrm{RR}=\mathrm{OR} /\left[\left(1-\mathrm{P}_{0}\right)+\left(\mathrm{P}_{0} \times \mathrm{OR}\right)\right]$, where $\mathrm{P}_{0}$ is the PTSDpositive rate in the control group [15]. All analyses were performed using SPSS version 11.0 (SPSS, Chicago), and the results were considered as statistically significant at $\mathrm{p}<0.05$.

\section{Results}

The rates for positive preflood behavioral characteristics were $45.29,49.89$, and $45.75 \%$ for 'health questions', 'behavioral questions', and 'habit questions', respectively. The median (minimum, maximum) scores in the positive populations were $2(1,12), 3(1,24)$, and $2(1,8)$ for 'health questions', 'behavioral questions', and 'habit questions', respectively. The overall rate for positive behavioral characteristics was $71.16 \%$, with a median score (minimum, maximum) of $4(1,33)$. A total of 144 children were classi-
Table 1. Prevalence of PTSD in subgroup populations exposed to floods in Hunan, China

\begin{tabular}{|c|c|c|c|c|}
\hline & \multirow{2}{*}{$\begin{array}{l}\text { Subjects } \\
\mathrm{n}\end{array}$} & \multicolumn{3}{|c|}{ Prevalence of PTSD } \\
\hline & & $\mathrm{n}$ & $\%$ & $\mathrm{p}$ \\
\hline \multicolumn{5}{|l|}{ Gender } \\
\hline Male & 3,730 & 79 & 2.12 & \\
\hline Female & 3,308 & 65 & 1.96 & 0.651 \\
\hline \multicolumn{5}{|l|}{ Age } \\
\hline $7-8$ & 1,460 & 21 & 1.44 & \\
\hline $9-10$ & 2,024 & 39 & 1.93 & \\
\hline $11-12$ & 1,753 & 23 & 1.31 & \\
\hline $13-14$ & 1,303 & 40 & 3.07 & \\
\hline $15-16$ & 498 & 21 & 4.22 & $<0.001$ \\
\hline \multicolumn{5}{|l|}{ Flood type } \\
\hline Soaked & 3,257 & 22 & 0.68 & \\
\hline Collapsed & 2,621 & 60 & 2.29 & \\
\hline Flash flood & 1,129 & 51 & 4.52 & $<0.001$ \\
\hline \multicolumn{5}{|l|}{ Flood severity } \\
\hline Mild & 2,955 & 12 & 0.41 & \\
\hline Moderate & 2,335 & 39 & 1.67 & \\
\hline Severe & 1,747 & 92 & 5.27 & $<0.001$ \\
\hline \multicolumn{5}{|c|}{ Surrounded by the water and waited for rescue } \\
\hline Yes & 227 & 5 & 2.20 & \\
\hline No & 6,667 & 139 & 2.08 & 0.813 \\
\hline \multicolumn{5}{|c|}{ Saw somebody drowned by the flood } \\
\hline Yes & 35 & 2 & 5.71 & \\
\hline No & 6,861 & 142 & 2.07 & 0.175 \\
\hline \multicolumn{5}{|c|}{ Family members scattered by the flood } \\
\hline Yes & 171 & 2 & 1.17 & \\
\hline No & 6,740 & 132 & 1.96 & 0.775 \\
\hline \multicolumn{5}{|c|}{$\begin{array}{l}\text { Delay in reopening of school or changing school because of } \\
\text { disaster }\end{array}$} \\
\hline Yes & 2,018 & 129 & 6.39 & \\
\hline No & 4,761 & 5 & 0.11 & $<0.001$ \\
\hline
\end{tabular}

fied as PTSD-positive, yielding an overall prevalence of $2.05 \%$. The PTSD prevalence for males and females was $2.12 \%(79 / 3730)$ and $1.96 \%(65 / 3,308)$, respectively. Prevalence of PTSD was highest among children from flash flood areas (4.52\%) and lowest among children from soaked flood areas $(0.59 \%)$ (table 1$)$. Table 1 also shows that age, flood type, flood severity, and 'delayed reopening of school or change of school because of flood' were significantly associated with PTSD ( $\mathrm{p}<0.001)$. There was no significant association between PTSD and 'surrounded by the water and waited for rescue', 'saw somebody drowned by the flood', and 'family members scattered by the flood'.

The relationship between positive PTSD and the children's behavioral problems is shown in table 2. Generally, the positive rate of PTSD increased with behavioral problem scores among the children assessed. 
Table 2. Relationship between preflood behavioral characteristics and positive PTSD among children exposed to floods in Hunan, China

\begin{tabular}{|c|c|c|c|c|c|}
\hline & $\mathrm{n}$ & $\begin{array}{l}\text { PTSD-positive } \\
\mathrm{n}(\%)\end{array}$ & $\mathrm{p}$ values & $\begin{array}{l}\text { RR } \\
(95 \% \mathrm{CI})\end{array}$ & $\begin{array}{l}\text { Adjusted }^{1} \mathrm{RR} \\
(95 \% \mathrm{CI})\end{array}$ \\
\hline \multicolumn{6}{|c|}{ Health questions score } \\
\hline 0 & 3,782 & $67(1.8)$ & & 1.00 & \\
\hline 1 & 1,491 & $13(0.9)$ & & $0.49(0.27-0.89)$ & $0.39(0.21-0.71)$ \\
\hline 2 & 1,037 & $8(0.8)$ & & $0.44(0.21-0.91)$ & $0.34(0.16-0.71)$ \\
\hline$\geq 3$ & 603 & $46(7.6)$ & 0.000 & $4.31(2.93-6.33)$ & $3.58(2.42-5.24)$ \\
\hline \multicolumn{6}{|c|}{ Behavioral questions score } \\
\hline 0 & 3,464 & $17(0.5)$ & & 1.00 & \\
\hline 1 & 823 & $4(0.5)$ & & $0.99(0.33-2.95)$ & $0.85(0.28-2.54)$ \\
\hline 2 & 735 & $53(7.2)$ & & $14.69(8.46-25.53)$ & $13.75(8.01-23.09)$ \\
\hline$\geq 3$ & 1,891 & $60(3.2)$ & 0.000 & $6.47(3.76-11.11)$ & $5.26(3.06-8.98)$ \\
\hline \multicolumn{6}{|c|}{ Habit questions score } \\
\hline 0 & 3,750 & $9(0.2)$ & & 1.00 & \\
\hline 1 & 1,082 & $4(0.4)$ & & $1.54(0.47-5.01)$ & $1.23(0.38-4.00)$ \\
\hline 2 & 1,190 & $12(1.0)$ & & $4.20(1.77-10.00)$ & $3.74(1.56-8.89)$ \\
\hline$\geq 3$ & 891 & $109(12.2)$ & 0.000 & $50.97(25.72-101.03)$ & $37.60(19.47-70.17)$ \\
\hline \multicolumn{6}{|c|}{ Total/overall score } \\
\hline 0 & 1,994 & $4(0.2)$ & & 1.00 & \\
\hline $1-2$ & 1,581 & $6(0.4)$ & & $1.89(0.53-6.72)$ & $1.82(0.51-6.43)$ \\
\hline $3-5$ & 1,654 & $63(3.8)$ & & $18.99(6.90-52.28)$ & $17.55(6.48-45.54)$ \\
\hline$\geq 6$ & 1,684 & $61(3.6)$ & 0.000 & $18.06(6.55-49.76)$ & $13.88(5.09-36.76)$ \\
\hline
\end{tabular}

${ }^{1}$ Adjusted using multivariate logistic regression, for age, sex, flood type, flood degree, waiting for rescue, observing a victim drowning, family members scattered by the flood, and delay in the reopening of school.

After adjusting for potential confounding variables, the positive rate of PTSD increased with 'health questions score', 'habit questions score', and the overall score, but not 'behavioral questions score' (table 2).

\section{Discussion}

Our study investigated 7,038 flood victims aged 7-15 years. The overall prevalence of PTSD was $2.05 \%$. Prevalence of symptom-specific PTSD was 13.77, 2.23, and $11.58 \%$ for criteria $B, C$, and $D$, respectively. To our knowledge, our study is the largest to assess the impact of behavioral characteristics on PTSD among children aged 7-15 years in a flood plain area. PTSD is a common psychological disorder in disaster-affected populations, and has been widely used to evaluate the psychological impact of natural disasters, accidents, and war victims $[7,12,16]$. We found significant relationships between PTSD and behavioral characteristics of the children assessed.

The $2.05 \%$ prevalence of PTSD among the children assessed in our study is lower than that observed in adult flood victims in China (8.6\%), survivors of the 1993 Great Midwest floods (23\%), and adult survivors of the 1999 floods in Mexico (24\%) [17-19]. The differences in prevalence of PTSD suggest that PTSD symptoms are influenced by the extent of flood, culture, and age. The PTSD prevalence observed in our study was also lower than that observed among children and adolescents affected by the tsunami in Thailand (7.6\%) [20]. This finding suggests that floods cause less psychological trauma than tsunamis among children.

Our study did not show any significant difference, in PTSD prevalence, between boys and girls. This finding does not compare well with a finding of lower PTSD prevalence among adult females in Hunan [17]. The difference in findings suggests that psychosocial differences between males and females remain marginal until adulthood.

The overall behavioral characteristics considered in our study showed a strong linear association with PTSD. In specific terms, characteristics related to health and habits showed a strong linear association with PTSD. This was not the case with items under the 'behavioral questions' category. It is our belief that children with high 
scores under this category might have received some treatment, thereby reducing their risk of PTSD. Although the real mechanism for this observation is unknown, Silva et al. [21] have shown that domestic violence or physical abuse are predictive of severe PTSD in children, and that preexisting aggressive behavior is common among victims of physical abuse. Further, cognitive capacity and personality have been found to be important determinants of psychological vulnerability in military-related trauma [22]. These findings suggest that behavioral problems among children have a strong relationship with PTSD. Our study also found that characteristics related to habits and behavioral questions had the greatest effect on PTSD while characteristics related to health had the least effect on PTSD. This observation can be explained by the fact that characteristics related to habits and behavioral problems are highly psychological in nature, and will therefore yield high prevalence of PTSD. Psychological interventions have indeed been shown to reduce disaster-related psychological distress [23].

\section{Conclusion}

Our study, which was based on a large sample, found that behavioral characteristics are an important factor influencing the prevalence of PTSD among flood victims aged 7-15 years. It is therefore important to give special attention to children with behavioral problems in times of floods to prevent or reduce the prevalence of PTSD.

\section{Acknowledgments}

This project was supported by grant CMB 98-689 from the Chinese Medicine Board (New York). The authors thank Linbao Xiang, Director of the Center for Disease Prevention and Control (CDC) of Yiyang City; Xiumin Zhang, Director of CDC of Anxiang county; Huaxian He, Director of CDC of Yueyang City; Linlin Li, Director of CDC of Xiangxi Autonomy; and Senlin Tang, Director of CDC of Datong Lake District, Hunan, China, for their cooperation in this study.

\section{References}

1 International Federation of Red Cross and Red Crescent Societies. World Disasters Report 2002. Http://www.ifrc.org/publicat/ wdr2002/chapter8.asp.

2 Wang X, Gao L, Shinfuku N, Zhang H, Zhao C, Shen Y: Longitudinal study of earthquake-related PTSD in a randomly selected community sample in north China. Am J Psychiatry 2000;157:1260-1266.

3 American Psychiatric Association: Diagnostic and Statistical Manual of Mental Disorders, ed 4. Washington, APA, 1994.

-4 Schnyder U, Moergeli H, Klaghofer R, Buddeberg C: Incidence and prediction of posttraumatic stress disorder symptoms in severely injured accident victims. Am J Psychiatry 2001;158:594-599.

-5 Liu GX, Yang LQ, Xu XD, Zhang HB, Hu SF, Wang XF: Study of posttraumatic stress disorder after traffic accident. Chin J Psychiatry 2002;16:18-20.

-6 Brewin CR, Andrews B, Rose S, Kirk M: Acute stress disorder and posttraumatic stress disorder in victims of violent crime. Am J Psychiatry 1999;156:360-366.

-7 Marshall RD, Bryant RA, Amsel L, Suh EJ, Cook JM, Neria Y: The psychology of ongoing threat: relative risk appraisal, the September 11 attacks, and terrorism-related fears. Am Psychol 2007;62:304-316.

-8 Heinrichs M, Wagner D, Schoch W, Soravia LM, Hellhammer DH, Ehlert U: Predicting posttraumatic stress symptoms from pretraumatic risk factors: a 2-year prospective follow-up study in firefighters. Am J Psychiatry 2005;162:2276-2286.

9 Zhou JC, Zhou CL, Zhang SG: Investigation of spirit reaction to rock fall and hanging bridge in Wuxi County. Chin J Psychiatry 1998;2:72-75.

10 Durkin MS, Khan N, Davidson LL, Zaman SS, Stein ZA: The effects of a natural disaster on child behavior: evidence for posttraumatic stress. Am J Public Health 1993;83:1549-1553.

11 Gibbs MS: Factors in the victim that mediate between disaster and psychopathology: a review. J Trauma Stress 1989;2:489-514.

12 Wong CK: The Rutter Parent Scale A2 and Teacher Scale B2 in Chinese. II. Clinical validity among Chinese children. Acta Psychiatr Scand 1988;78:11-17

13 Kessler RC, Sonnega A, Bromet E, Hughes M, Nelson CB: Posttraumatic stress disorder in the National Comorbidity Survey. Arch Gen Psychiatry 1995;52:1048-1060.

14 Rutter M: A children's behaviour questionnaire for completion by teachers: preliminary findings. J Child Psychol Psychiatry 1967;8:1-11.

15 Zhang J, Yu KF: What's the relative risk? A method of correcting the odds ratio in cohort studies of common outcomes. JAMA 1998;280:1690-1691.

-16 Coker AL, Hanks JS, Eggleston KS, Risser J, Tee PG, Chronister KJ, Troisi CL, Arafat R, Franzini L: Social and mental health needs assessment of Katrina evacuees. Disaster Manag Response 2006;4:88-94.
17 Liu A, Tan H, Zhou J, Li S, Yang T, Wang J, Liu J, Tang X, Sun Z, Wen SW: An epidemiologic study of posttraumatic stress disorder in flood victims in Hunan China. Can J Psychiatry 2006;51:350-354.

18 McMillen C, North C, Mosley M, Smith E: Untangling the psychiatric comorbidity of posttraumatic stress disorder in a sample of flood survivors. Compr Psychiatry 2002;43:478-485.

19 Norris FH, Murphy AD, Baker CK, Perilla JL: Postdisaster PTSD over four waves of a panel study of Mexico's 1999 flood. J Trauma Stress 2004;17:283-292.

20 Piyasil V, Ketuman P, Plubrukarn R, Jotipanut V, Tanprasert S, Aowjinda S, Thaeeromanophap S: Post traumatic stress disorder in children after tsunami disaster in Thailand: 2 years follow-up. J Med Assoc Thai 2007;90:2370-2376.

21 Silva RR, Alpert M, Munoz DM, Singh S, Matzner F, Dummit S: Stress and vulnerability to posttraumatic stress disorder in children and adolescents. Am J Psychiatry 2000; 157:1229-1235.

22 Qouta S, Punamäki RL, Montgomery E, El Sarraj E: Predictors of psychological distress and positive resources among Palestinian adolescents: trauma, child, and mothering characteristics. Child Abuse Negl 2007;31:699-717.

23 Chemtob CM, Tomas S, Law W, Cremniter D: Postdisaster psychosocial intervention: a field study of the impact of debriefing on psychological distress. Am J Psychiatry 1997; 154:415-417. 